\title{
A Study of Point Defects in the B2-Phase Region of the Fe-Al System by Mössbauer Spectroscopy
}

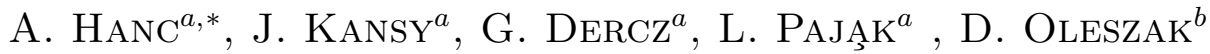 \\ AND J. MRZIGOD ${ }^{c}$ \\ ${ }^{a}$ Institute of Materials Science, Silesian University \\ Bankowa 12, 40-007 Katowice, Poland \\ ${ }^{b}$ Faculty of Materials Science and Engineering \\ Warsaw University of Technology \\ Wołoska 141, Warsaw, Poland \\ ${ }^{c}$ Institute of Chemistry, Silesian University \\ Szkolna 9, 40-007 Katowice, Poland
}

\begin{abstract}
In this work, we employed the Mössbauer spectroscopy and X-ray powder diffraction in a study of point defect formation in intermetallic phases of the $B 2$ structure of the $\mathrm{Fe}-\mathrm{Al}$ system as a function of $\mathrm{Al}$ concentration. The results are compared with the concentrations of point defect determined from positron annihilation data. In the Mössbauer effect, two types of samples are investigated: $\mathrm{Fe}-\mathrm{Al}$ alloys with few additives obtained by induction melting and Al-rich metallic powders produced by the self-decomposition method and intensive grinding of high energy in the electro-magneto-mechanical mill. We present the values of the ${ }^{57} \mathrm{Fe}$ isomer shift and quadrupole splitting for the components describing the point defect in the local environment of a Mössbauer nuclide. The concentration of the Fe vacancies and Fe atoms substituting $\mathrm{Al}(\mathrm{Fe}-\mathrm{AS})$ are determined. The results showed that an increase in $\mathrm{Al}$ content causes an increase in vacancy and $\mathrm{Fe}-\mathrm{AS}$ concentration.
\end{abstract}

PACS numbers: 75.50.Bb, 61.72.J-, 76.80.+y

\section{Introduction}

Iron aluminides represent an intriguing class of new materials: they offer a good combination of mechanical properties, specific weight/strength ratio, corrosion and oxidation resistance and low raw material cost [1-3], which makes

*corresponding author; e-mail: ahanc@us.edu.pl 
them potential candidates for the substitution of stainless steel in applications at moderate to high temperatures. The extensive technological application of iron aluminides, however, is impaired by their low room temperature tensile ductility. This is attributed to extrinsic (environmental embitterment) or intrinsic (low grain boundary cohesion) mechanisms, with the dominant mechanism depending on the aluminum content of the alloy. The development of new, more ductile Fe$\mathrm{Al}$ alloys depends on a thorough understanding of their properties, implicating a better comprehension of the properties and behavior of defect in these materials. Experimental as well as theoretical studies [1-16] suggest that point defects in iron aluminides present complex, especially triple defect structure. It is well known that upon rapid quenching from elevated temperatures, iron aluminides retain a high concentration of thermal vacancies, which frozen, increase their yield strength and hardness at room temperature [1-3]. It is expected that the concentration of point defect can be strongly affected by the variation of $\mathrm{Al}$ content and the composition modification of the aluminides by transition metal ternary additives [3, 4].

In this paper, we employ the Mössbauer spectroscopy and X-ray powder diffraction (XRD) in a study of point defect formation in intermetallic phases of the $B 2$ structure of the $\mathrm{Fe}-\mathrm{Al}$ system. Two types of samples are investigated: $\mathrm{Fe}-\mathrm{Al}$ ( $\mathrm{Al}$ content below 50 at.\%) with small additives and metallic powders of $\mathrm{Fe}-\mathrm{Al}$ ( $\mathrm{Al}$ above 50 at.\%) obtained by the self-decomposition method and intensive grinding $[17,18,12-15]$. Mössbauer spectra are analyzed with a model [7] according to which the vacancies and $\mathrm{Fe}$ atoms substituting $\mathrm{Al}(\mathrm{Fe}-\mathrm{AS})$ in atomic shells close to probe atom, influence the isomer shift and quadrupole splitting of particular spectrum components. The concentrations of point defects are determined from the intensities of these components and they are correlated with the changes of $\mathrm{Al}$ content.

\section{Experimental details}

The chemical compositions of the investigated samples are presented in Table I. The $\mathrm{Fe}-\mathrm{Al}$ (Fe-rich) samples were obtained from Armco iron, aluminum of 99.99\% purity, and a small amount of other additives added in order to improve the thermal and mechanical properties of alloys. The samples were prepared by melting in spinel $\mathrm{Al}_{2} \mathrm{O}_{3} \times \mathrm{MgO}$ crucibles in an induction furnace at vacuum of $10^{-2}$ Torr. The ingots were re-melted three times to insure homogeneity and annealed in a vacuum furnace for $48 \mathrm{~h}$ and then cooled down slowly with the furnace. The Fe-Al (Al-rich) samples were produced by the self-decomposition method [17] and intensive grinding in the high-energy electro-magneto-mechanical mill [18].

Phase analysis was carried out by applying X-ray diffraction using X-ray Philips diffractometer equipped with graphite monochromator. The $\mathrm{Cu} K_{\alpha}$ radiation was used. The samples were rotated during X-ray data collection. Selected X-ray diffraction patterns of $\mathrm{Fe}_{62} \mathrm{Al}_{38}$ and $\mathrm{Fe}_{55} \mathrm{Al}_{45}$ samples are presented in Fig. 1. The features of $B 2$-type structure prevail in the diffraction spectra. Lattice constant parameters and long-range order parameters determined by the Rietveld 
TABLE I

Chemical compositions of the investigated materials [at.\%].

\begin{tabular}{c|c|c|c|c|c}
\hline \hline \multirow{2}{*}{} & \multicolumn{5}{|c}{ Contents [at.\%] } \\
\cline { 2 - 6 } & $\mathrm{I}^{a}$ & $\mathrm{II}^{a}$ & $\mathrm{III}^{b}$ & $\mathrm{IV}^{c}$ & $\mathrm{~V}^{c}$ \\
\hline $\mathrm{Fe}$ & 61.64 & 54.64 & 48 & 46 & 44 \\
$\mathrm{Al}$ & 38 & 45 & 52 & 54 & 56 \\
\hline Additions & Mo-0.20; $\mathrm{Zr}-0.05 ;$ & \multicolumn{4}{|c}{-} \\
& \multicolumn{7}{|c}{ C-0.1; B-0.01 } & \multicolumn{3}{|c}{} \\
\hline
\end{tabular}

${ }^{a}$ material prepared using the gravity casting technique; ${ }^{b}$ material after self-decomposition process and milling; ${ }^{c}$ material after self-decomposition process

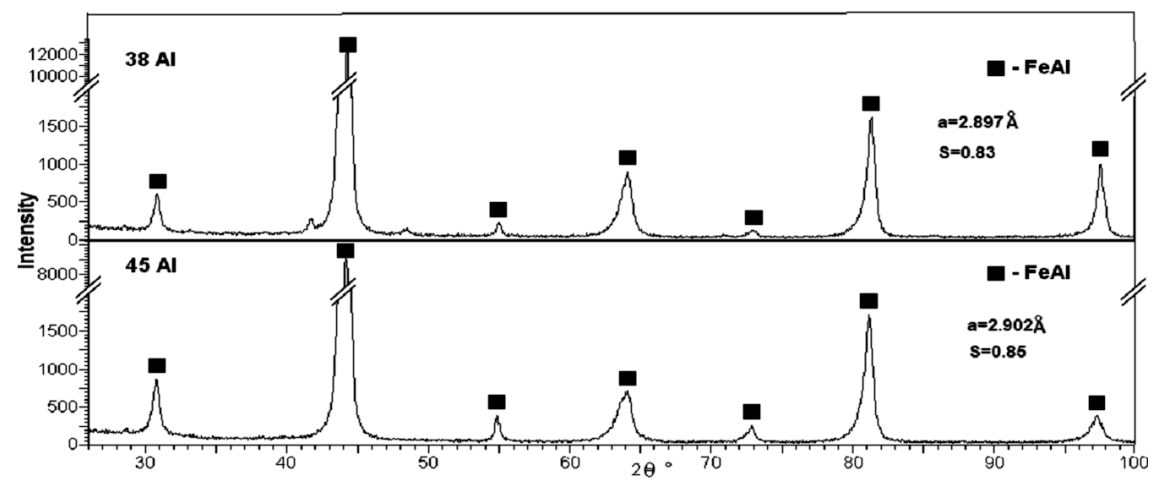

Fig. 1. X-ray diffraction patterns of $\mathrm{Fe}_{62} \mathrm{Al}_{38}$ and $\mathrm{Fe}_{55} \mathrm{Al}_{45}$ samples annealed at $1000^{\circ} \mathrm{C}$ for $48 \mathrm{~h}$.

refinement method show the tendency to increase with the increase in aluminum content in the samples.

The ${ }^{57} \mathrm{Fe}$ Mössbauer spectra were measured in transmission geometry at room temperature by means of a constant-acceleration spectrometer of the standard design. The $14.4 \mathrm{keV}$ gamma rays were provided by a $50 \mathrm{mCi}$ source of ${ }^{57} \mathrm{Co} / \mathrm{Rh}$. Hyperfine parameters of the investigated spectra were related to the $\alpha$ Fe standard. Experimental spectrum shape was described with a transmission integral calculated according to the numerical Gauss-Legendre procedure [19] which enables determination of real intensities of fitted components.

\section{Results and discussion}

The selected Mössbauer spectra are presented in Fig. 2. All Mössbauer spectra were fitted with the model proposed by Bogner et al. [7]. The Mössbauer spectrum of $\mathrm{Fe}_{55} \mathrm{Al}_{45}$ sample fitted with this model is shown in Fig. 3. According to this model, the spectrum contains four components describing different local 


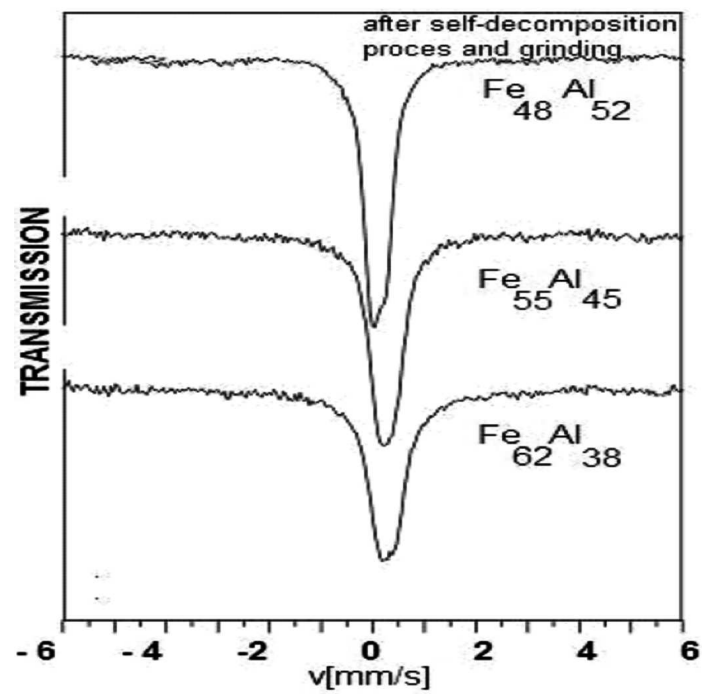

Fig. 2. The ${ }^{57} \mathrm{Fe}$ Mössbauer transmission spectra for $\mathrm{Fe}_{62} \mathrm{Al}_{38}, \mathrm{Fe}_{55} \mathrm{Al}_{45}$ alloys annealed for $48 \mathrm{~h}$ at $1000^{\circ} \mathrm{C}$ and $\mathrm{Fe}_{48} \mathrm{Al}_{52}$ obtained by self-decomposition method and intensive grinding.

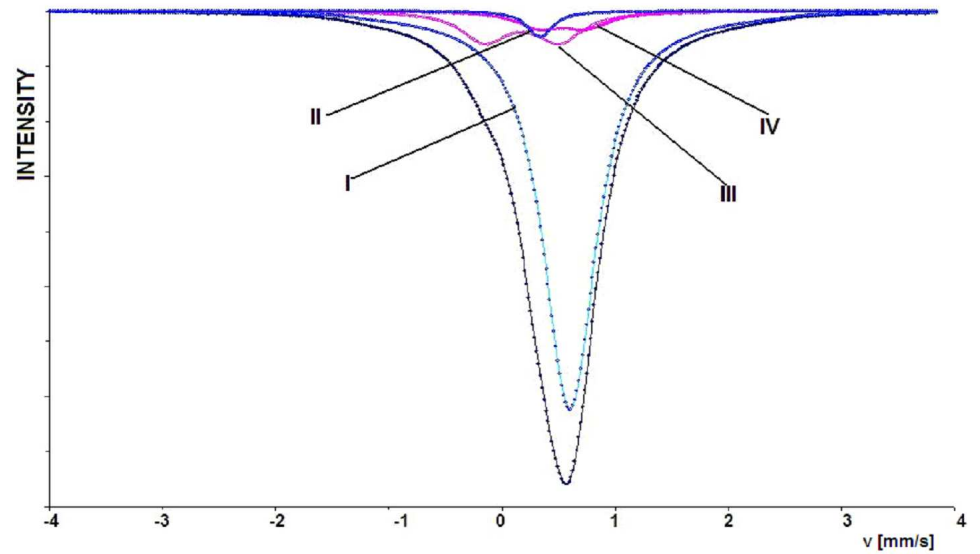

Fig. 3. The Mössbauer transmission spectrum for the $\mathrm{Fe}_{65} \mathrm{Al}_{45}$ alloys. The best fit and components are drawn with the lines, points present the experimental data.

environments of a ${ }^{57} \mathrm{Fe}$ nuclide. The first component (I) - a single line - represents an ordered $B 2$ structure. The second component (II) - a single line (which approximates an unresolved quadrupole doublet) - relates to the case when the Mössbauer Fe nuclide is located in a corner of the cubic centered unit, and an $\mathrm{Fe}-\mathrm{AS}$ atom is situated in the center of this unit. The third component (III) - a doublet of lines (which approximates an unresolved Zeeman sextet) - corresponds to a Fe atom located in the Fe-AS position. The fourth component (IV) - also a 
quadrupole doublet of lines - represents the case where there is a vacancy in the near Fe surrounding.

TABLE II

Values of hyperfine parameters (IS, QS); W - line width and A - subspectral area.

\begin{tabular}{|c|c|c|c|c|c|}
\hline Samples & Component & $\begin{array}{c}\mathrm{IS}^{*, * *} \\
{[\mathrm{~mm} / \mathrm{s}]}\end{array}$ & $\begin{array}{c}\mathrm{QS}^{*} \\
{[\mathrm{~mm} / \mathrm{s}]}\end{array}$ & W & $\begin{array}{c}\text { A } \\
{[\%]}\end{array}$ \\
\hline \multirow{4}{*}{$\mathrm{Fe}_{63} \mathrm{Al}_{38}{ }^{\mathrm{a}}$} & L-I & 0.19 & & 0.27 & 83 \\
\hline & L-II & 0.06 & & 0.34 & 14 \\
\hline & Q-III & 0.04 & 0.25 & 0.36 & 1.9 \\
\hline & Q-IV & 0.23 & 0.13 & 0.29 & 1.1 \\
\hline \multirow{4}{*}{$\mathrm{Fe}_{55} \mathrm{Al}_{45}{ }^{\mathrm{a}}$} & L-I & 0.24 & & 0.25 & 85 \\
\hline & L-II & 0.07 & & 0.32 & 11.7 \\
\hline & Q-III & 0.05 & 0.22 & 0.34 & 2.1 \\
\hline & Q-IV & 0.21 & 0.17 & 0.26 & 1.2 \\
\hline \multirow{4}{*}{$\mathrm{Fe}_{48} \mathrm{Al}_{52}{ }^{\mathrm{b}}$} & L-I & 0.25 & & 0.31 & 84 \\
\hline & L-II & 0.09 & & 0.29 & 12 \\
\hline & Q-III & 0.06 & 0.31 & 0.35 & 2.3 \\
\hline & Q-IV & 0.29 & 0.19 & 0.31 & 1.7 \\
\hline \multirow{4}{*}{$\mathrm{Fe}_{46} \mathrm{Al}_{54}{ }^{\mathrm{c}}$} & L-I & 0.27 & & 0.26 & 78 \\
\hline & L-II & 0.17 & & 0.29 & 16.6 \\
\hline & Q-III & 0.09 & 0.33 & 0.33 & 3.1 \\
\hline & Q-IV & 0.30 & 0.21 & 0.33 & 2.3 \\
\hline \multirow{4}{*}{$\mathrm{Fe}_{44} \mathrm{Al}_{56}{ }^{\mathrm{c}}$} & L-I & 0.33 & & 0.26 & 75 \\
\hline & L-II & 0.18 & & 0.28 & 19 \\
\hline & Q- III & 0.11 & 0.37 & 0.32 & 3.3 \\
\hline & Q-IV & 0.34 & 0.23 & 0.32 & 2.7 \\
\hline
\end{tabular}

${ }^{*}$ Error estimated from the fitting procedure is equal to \pm 0.005 .

${ }^{* *}$ Relative to the $\alpha$-Fe foil at room temperature.

${ }^{a}$ material prepared using the gravity casting technique;

${ }^{b}$ material after self-decomposition process and milling;

${ }^{c}$ material after self-decomposition process.

In Table II, we present the evolution of the values of the isomer shift (IS) and quadrupole splitting (QS) of the spectra components depending on the aluminum concentration. Similar values of the IS and QS for the components describing the ordered $B 2$ structure and the point defect were observed in theoretical calculations [20] and experimental research [7, 9, 13, 14]. The values of vacancy and anti-site atoms concentrations found using the described model are shown in Table III. 
TABLE III

Values of vacancy and anti-site atom $\mathrm{Fe}-\mathrm{AS}$ concentrations in the samples of $\mathrm{Fe}-\mathrm{Al}$ determined with the Mössbauer spectroscopy investigations.

\begin{tabular}{c|c|c}
\hline \hline $\begin{array}{c}\text { Estimated } \\
\text { phase composition }\end{array}$ & $\begin{array}{c}\text { Vacancy concentration } \\
\mathrm{V}_{\mathrm{Fe}}[\%]^{*}\end{array}$ & $\begin{array}{c}\text { Concentration } \\
\mathrm{Fe}-\mathrm{As}[\%]^{* *}\end{array}$ \\
\hline $\mathrm{Fe}_{62} \mathrm{Al}_{38}{ }^{\mathrm{a}}$ & 0.04 & 1.9 \\
$\mathrm{Fe}_{55} \mathrm{Al}_{45}{ }^{\mathrm{a}}$ & 0.05 & 2.1 \\
$\mathrm{Fe}_{48} \mathrm{Al}_{52}{ }^{\mathrm{b}}$ & 0.07 & 2.3 \\
$\mathrm{Fe}_{46} \mathrm{Al}_{54}{ }^{\mathrm{c}}$ & 0.09 & 3.1 \\
$\mathrm{Fe}_{43} \mathrm{Al}_{56}{ }^{\mathrm{c}}$ & 0.10 & 3.3 \\
\hline
\end{tabular}

\footnotetext{
*Error estimated is equal to \pm 0.006 .

${ }^{* *}$ Error estimated is equal to \pm 0.05 .

${ }^{a}$ material prepared using the gravity casting technique;

${ }^{b}$ material after self-decomposition process and milling;

${ }^{c}$ material after self-decomposition process.
}

To estimate the value for the concentration of vacancies on the Fe sublattice, the intensity of a subspectrum was divided by 26 [7]. The obtained values of concentrations of vacancies and anti-site atoms ( $\mathrm{Fe}-\mathrm{AS})$ show an increase with $\mathrm{Al}$ content, which confirms the results of theoretical calculations [10] and some experimental data $[7,8,13,14,16]$. According to the literature $[3-8,9,11]$, vacancies in the $\mathrm{Fe}$ sublattice $\mathrm{V}_{\mathrm{Fe}}$ are the dominant type of defects in $\mathrm{Fe}-\mathrm{Al}$ system (maybe organized in triple defects, i.e. two vacancies and an anti-site atom $[5,8]$ ). Vacancy formation in Fe-rich Fe-Al alloys has been studied by Schaefer et al. [21] using the positron lifetime technique. They found that the thermal vacancy concentration is about $2.3 \times 10^{-5}$ at $600^{\circ} \mathrm{C}$, increasing to about $1.3 \times 10^{-3}$ at $900^{\circ} \mathrm{C}$. We also carried out a study of vacancies formation in alloys I and II (see Table I) as a function of $\mathrm{Al}$ concentration [16]. We observe that the total concentration of defects is so high that the positrons are exclusively trapped by defects. Above 38 at.\% $\mathrm{Al}$, vacancies in $\mathrm{Al}$ sublattice $\left(\mathrm{V}_{\mathrm{Al}}\right)$ are formed in a minor amount, in comparison to the vacancies in Fe sublattice $\left(\mathrm{V}_{\mathrm{Fe}}\right)$.

The values of vacancies concentrations in the samples containing micro-additions (I and II - see Table I), estimated in this work, are slightly lower than vacancies concentrations in $\mathrm{Fe}_{x} \mathrm{Al}_{1-x}(x>0.5)$ alloys, calculated in theoretical papers $[10]$ and then some experimental data $[7,8]$. We connect this result with a defect and electron structure modification in the examined materials by the micro-additions. Such a character of the defect structure, mainly the lowered concentration of vacancies in the alloys modified with micro-additions, confirms the advisability of their introduction in order to improve plasticity of these materials.

The values of point defect concentrations in the $\mathrm{Fe}-\mathrm{Al}$ metallic powders (samples III-V, see Table I) obtained by milling after self-decomposition process have 
shown much higher concentration of vacancies than that in the samples $\mathrm{Fe}_{62} \mathrm{Al}_{38}$ and $\mathrm{Fe}_{55} \mathrm{Al}_{45}$ (samples I and II). That suggests a decrease in energy of vacancies formation in Al-rich alloys. However, the determined concentration of point defects in the samples III-V is even higher than those described in literature $[3,7-9,11]$. This very high concentration of vacancies in the metallic powders can be related to their preparation by self-decomposition method and milling process.

\section{Conclusions}

In this work point defect concentrations for the series of intermetallic compound samples $\mathrm{Fe}-\mathrm{Al}$ were determined applying the Mössbauer spectroscopy. It was found that the investigated materials contain high concentrations of point defects, which significantly increases with the increase in aluminum content. The values of vacancies concentrations in the $\mathrm{Fe}_{x} \mathrm{Al}_{1-x}(x>0.5)$ samples containing micro-additions, estimated in this work, are slightly lower than vacancies concentrations in $\mathrm{Fe}_{x} \mathrm{Al}_{1-x}(x>0.5)$ alloys determined by other authors. Such a character of the defect structure - mainly the lowered concentration of vacancies in the alloys modified with micro-additions - confirms the advisability of their introduction in order to improve plasticity of these materials.

A comparison of point defects concentrations in materials obtained by various methods (melting, self-decomposition, and milling) indicates a complexity of the factors influencing the defect structure of the materials.

The higher concentrations of point defect in the Al-rich region samples (III-V) in comparison to the $\mathrm{Fe}_{62} \mathrm{Al}_{38}$ and $\mathrm{Fe}_{55} \mathrm{Al}_{45}$ samples, suggest that a decrease in vacancies concentrations in the metallic powders can be related to their preparation by self-decomposition method and milling process.

\section{Acknowledgments}

The work was supported by the State Committee for Scientific Research, grant no. PB-581/T/2006.

\section{References}

[1] C.G. McKamey, Physical Metallurgy and Processing of Intermetallic Compounds, Chapman\&Hall, New York 1996, p. 351.

[2] P.R. Munroe, Processing, Properties and Applications Proceedings of ASM, Eds. S.H. Whang, C.T. Liu, D.P. Pope, J.D. Stiegle, Materials Society, Warrenale 1996, p. 96.

[3] J.L. Jordan, S.C. Deevi, Intermetallics 11, 507 (2003).

[4] D.G. Morris, M.A. Morris-Muñoz, Intermetallics 7, 1121 (1999).

[5] M. Kogachi, T. Haraguchi, S.M. Kim, Intermetallics 6, 499 (1998).

[6] M. Hillert, M. Selleby, J. Alloys Comp. 329, 208 (2001).

[7] J. Bogner, W. Steiner, M. Reissner, P. Mohn, P. Blaha, K. Schwarz, R. Krachler, H. Ipser, B. Sepiol, Phys. Rev. B 58, 14922 (1998). 
[8] A. Broska, J. Wolff, M. Franz, Th. Hehenkamp, Intermetallics 7, 259 (1999).

[9] S. Gianella, R.S. Bursa, W. Deng, F. Marino, T. Spataru, G. Principi, J. Alloys Comp. 317-318, 485 (2001).

[10] X. Ren, K. Otsuka, Philos. Mag. A 80, 467 (2000).

[11] T. Haraguchi, M. Kogachi, S.M. Kim, Intermetallics 7, 981 (1999).

[12] A. Hanc, G. Dercz, J.E. Frąckowiak, L. Pająk, F. Binczyk, in: Proc. of the XIX Conf. on Applied Crystallography, Eds. H. Morawiec, D. Stróż, World scientific, Singapore 2004, p. 312.

[13] A. Hanc, J.E. Frạckowiak, Nukleonika 49, S3, 7 (2004).

[14] A. Hanc, J.E. Frạckowiak, Nukleonika 52, S3, 24 (2006).

[15] A. Hanc, J.E. Frạckowiak, G. Dercz, L. Pajạk, Solid State Phenom. 130, 181 (2006).

[16] J. Kansy, A. Hanc, D. Giebel, M. Jabłońska, Acta Phys. Pol. A 113, 1409 (2008).

[17] F. Binczyk, Inżynieria Materiatowa 4, 51 (1989).

[18] F. Binczyk, W. Polechoński, S.J. Skrzypek, Powder Technology 114, 237 (2001).

[19] A. Ralston, A first course In numerical analysis, McGraw-Hill Book Company, London 1975.

[20] T. Michalecki, J. Deniszczyk, J.E. Frąckowiak, Nukleonika 49, S3, 3 (2004).

[21] H.E. Schaefer, R. Wurschum, M. Sob, T. Zak, W.Z. Yu, W. Eckert, F. Banhart, Phys. Rev. B 41, 11869 (1990). 